\title{
Post-market drug surveillance projects developing slowly
}

Published at www.cmaj.ca on Nov. 9

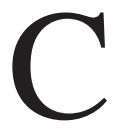

linical trials are considered by many to be the gold standard for pharmaceutical research, but real-world outcomes don't always match those discovered in a lab. Though clinical trials provide invaluable information about the safety and efficacy of drugs, they are conducted in controlled environments with a set number of people for limited periods of time. These limitations mean that research conducted before a drug reaches the consumer market could be considered a prelude to a story that has yet to be told.

"There are gaps in the evidence available," Diane Forbes, associate director of the Drug Safety and Effectiveness Network (DSEN), told delegates to the seventh Canadian Annual Meeting of the Drug Information Association in Ottawa, Ontario.

The DSEN, a post-market drug surveillance project spearheaded by Health Canada and the Canadian Institutes of Health Research (CIHR), is being designed to fill those gaps, Forbes added. Similar projects are currently under development in the United States (the Sentinel Initiative) and Europe (the European Network of Centres for Pharmacoepidemiology and Pharmacovigilance).

Increased monitoring of consumer drugs in Canada was highlighted as a need in the federal government's Food and Consumer Safety Action Plan in 2007. The government officially launched the DSEN project in July 2008. That was followed by a January announcement that the government would provide $\$ 32$ million over five years to create the network and $\$ 10$ million annually thereafter. The network is projected to be fully operational by fiscal year 2012/2013.

The network will consist of three main components: a virtual network of centres of excellence in post-market

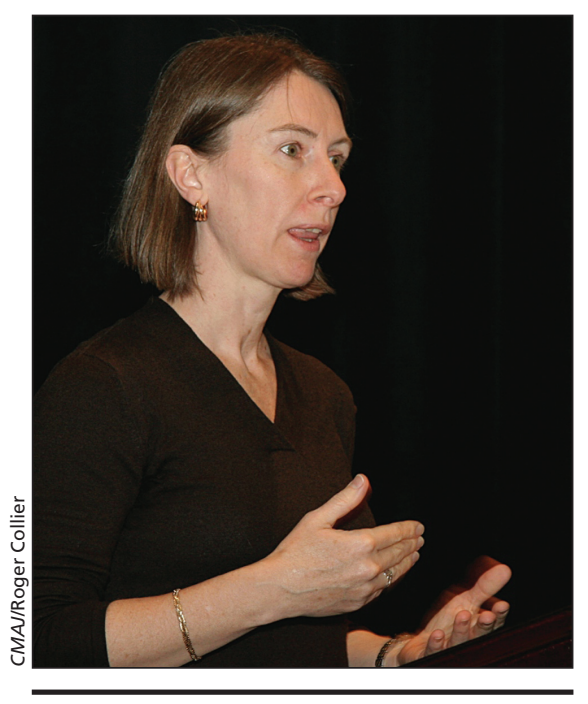

Creating the Canadian Drug Safety and Effectiveness Network is posing challenges, such as developing a common prioritized research agenda, but it's achievable, says Diane Forbes, associate director of the network.

drug research, a coordinating office to manage network operations and a steering committee to provide strategic direction. The main objectives for establishing this network are "to increase the available evidence on drug safety and effectiveness available to regulators, policy-makers, health care providers and patients; and, to increase capacity within Canada to undertake high-quality post-market research in this area," according to the DSEN website (www.cihr-irsc.gc.ca/e /39389.html).

Creating the network will pose various challenges, such as developing a common prioritized research agenda, but it's achievable, said Forbes. "The DSEN is quite new but there are existing programs at CIHR that we can draw upon."

The Sentinel Initiative was launched in May 2008 by the US Food and Drug Administration (FDA) to monitor the safety of drugs, biologics and medical devices. It is intended to be more proactive than existing systems that track adverse events, which rely on doctors, patients and producers of medical products to report medical mishaps.

"In our passive reporting system, there is a time lag in assessing issues," Judith Racossin, scientific lead of the Sentinel Initiative, told delegates via telephone.

In 2007, US Congress mandated the FDA to create an active surveillance system as part of the FDA Amendments Act. The initiative will ultimately result in the Sentinel System - a national electronic network that will draw upon health care data from multiple sources to monitor the safety of drugs and other medical products in real time. The FDA has already signed agreements to gain access to health care data from private insurers and the Center for Medicare and Medicaid Services. Academics, industry representatives and members of the public are being consulted on how to implement the complex system.

"This is a long-term project and will evolve," said Racossin.

Led by the European Medicines Agency, the European Network of Centres for Pharmacoepidemiology and Pharmacovigilance, aims to strengthen post-market surveillance of medicinal products across Europe.

"The traditional reactive approach to pharmacovigilance has resulted in inadequate data resources," Henry Fitt, a specialized group leader with the European Medicines Agency, told delegates via telephone.

Started in 2006, the European network has 92 centres in 21 countries, including new ones in Germany, Sweden, Ireland, Portugal and Greece. The primary goals for this year included creating a set of research standards, a code of conduct and a database for storing research. - Roger Collier, CMAJ

\section{DOI:10.1503/cmaj.109-3103}

